\title{
Association Between Race, Neighborhood, and Medicaid Enrollment and Outcomes in Medicare Home Health Care
}

\author{
Karen E. Joynt Maddox, MD, MPH, *广D Lena M. Chen, MD, MA, ${ }^{\dagger+}$ Rachael Zuckerman, PhD, ${ }^{\dagger}$ \\ and Arnold M. Epstein, MD, MS $S^{\text {\ब }}$
}

BACKGROUND/OBJECTIVES: More than 3 million Medicare beneficiaries use home health care annually, yet little is known about how vulnerable beneficiaries fare in the home health setting. This is particularly important given the recent launch of Medicare's Home Health ValueBased Purchasing model. The objective of this study was to determine odds of adverse clinical outcomes associated with dual enrollment in Medicaid and Medicare as a marker of individual poverty, residence in a low-income ZIP code tabulation area (ZCTA), and black race.

DESIGN: Retrospective observational study using individuals-level logistic regression.

SETTING: Home health care.

PARTICIPANTS: Fee-for-service Medicare beneficiaries from 2012 to 2014.

MEASUREMENTS: Thirty- and 60-day clinical outcomes, including readmissions, admissions, and emergency department (ED) use.

RESULTS: Home health agencies serving a high proportion of dually enrolled, low-income ZCTA, or black beneficiaries were less often high-quality. Dually-enrolled, low-income ZCTA, and Black beneficiaries receiving home health care after hospitalization had higher risk-adjusted odds of 30-day readmission (odds ratio $[\mathrm{OR}]=1.08$, $P<0.001 ;$ OR $=1.03, P<0.001 ;$ and $\mathrm{OR}=1.02, P=$ 0.002 respectively) and 30 -day $\mathrm{ED}$ use $(\mathrm{OR}=1.20,1.07$, and 1.15, $P<0.001$ for each). Those receiving home health care without preceding hospitalization had higher 60-day admission $(\mathrm{OR}=1.06, P<0.001 ; \mathrm{OR}=1.01, P=$ 0.002 ; and $\mathrm{OR}=1.05, P<0.001)$, and 60 -day $\mathrm{ED}$ use $(\mathrm{OR}=$ $1.16,1.03$, and $1.19, P<0.001$ for each). Differences were

From the *Washington University School of Medicine, St. Louis, Missouri; ${ }^{\dagger}$ Office of the Assistant Secretary for Planning and Evaluation, Department of Health and Human Services, Washington, District of

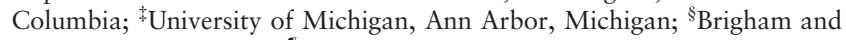
Women's Hospital; and "Harvard T.H. Chan School of Public Health, Harvard University, Boston, Massachusetts.

Address correspondence to Karen E. Joynt Maddox, 660 S. Euclid Ave., St. Louis, MO 63130. E-mail: kjoyntmaddox@wustl.edu

See related editorial by Chanee Fabius.

DOI: $10.1111 /$ jgs. 15082 primarily within agencies rather than between the agencies where these beneficiaries sought care.

CONCLUSION: Medicare beneficiaries receiving home health services who are dually enrolled, live in a lowincome neighborhood, or are black have higher rates of adverse clinical outcomes. These populations may be an important target for quality improvement under Home Health Value-Based Purchasing. J Am Geriatr Soc 66:239246, 2018.

Key words: home health; readmission; disparities; value-based purchasing

$M$ ore than three million Medicare beneficiaries use home health care annually, and Medicare spending on home health care totaled nearly $\$ 18$ billion in $2014 .{ }^{1} \mathrm{~A}$ home health agency (HHA) provides home health care, which includes services such as part-time or intermittent skilled nursing, physical therapy, and occupational therapy and home health aide services such as personal care and assistance with preparing meals, in a beneficiary's home on a visiting basis. With the proportion of the population aged 65 and older projected to near $22 \%$ by $2040,{ }^{2}$ the need for such services will grow.

Lower-cost settings such as home health care may be a critical component of ongoing efforts to improve quality and reduce costs of care as pressure to do so mounts across the healthcare system. The Centers for Medicare and Medicaid Services (CMS) recently announced the launch of a mandatory national Home Health Value-Based Purchasing model (HHVBP) in nine states. ${ }^{3}$ HHAs will receive bonuses or penalties based on performance on a range of quality measures, including unplanned hospitalizations and $\mathrm{ED}$ use. The HHVBP model, which will affect payments in 2018, puts a significant amount of HHAs' payment at risk-up to $8 \%$ by 2022 - and has the potential to be implemented nationally if it improves quality and reduces costs or is costneutral to Medicare. As value-based payment programs become increasingly prevalent across care settings, there is rising concern about how such programs will affect 
providers who serve individuals with social risk factors and, consequently, access to care for such individuals. ${ }^{4-6}$

Little is known about how vulnerable beneficiaries, such as those living in poverty and racial minorities, fare in the home health setting. Some research suggests that black individuals have worse functional outcomes ${ }^{7}$ and worse experiences $^{8}$ with home health care and that individuals from neighborhoods with high proportions of black residents have higher readmission rates from home health. ${ }^{9}$ Although a recent Department of Health and Human Services report examined some of these issues, ${ }^{10}$ there are no peer-reviewed data to our knowledge examining the relationship between black race and other home health outcomes such as preventable admissions and ED use or the relationship between poverty and outcomes in the home health setting.

We therefore set out to answer three research questions. First, do beneficiaries who are poor, identified as those dually enrolled in Medicaid and Medicare or living in low-income neighborhoods, or black receive care from lower-quality home health agencies than other beneficiaries? Second, do these beneficiaries have higher rates of unplanned hospitalization, rehospitalization, or ED use while receiving home health care? Third, if so, are worse outcomes due primarily due to individual factors or to the agencies from which these beneficiaries receive care?

\section{METHODS}

\section{Data}

We used the Medicare enrollment database and home health, inpatient, outpatient, and skilled nursing facility claims data from 2012 to 2014 to examine all four National Quality Forum-endorsed claims-based outcome measures used in the current Home Health Quality Reporting Program from CMS. This includes two pairs of measures; one pair examines outcomes in the 30 days after hospitalization (roughly one-third of home health stays follow a hospitalization), and one pair examines outcomes in the first 60 days of a home health stay, regardless of whether a hospitalization preceded the stay.

\section{Posthospitalization Outcomes}

The two measures of posthospitalization outcomes were readmission during the first 30 days of HHA care and ED use without readmission during the first 30 days of HHA care. These measures apply only to home health stays preceded by a hospitalization and use 3 years of data for performance measurement. Detailed methodology can be found on the CMS website; ${ }^{11}$ stays are included in the measure if they begin within 5 days of a hospitalization, unless the hospitalization was for treatment of cancer, primary psychiatric disease, or rehabilitation or the beneficiary was discharged against medical advice. Of the 10,022,072 Medicare home health stays from 2012 to 2014, 6,813,418 were excluded because a hospitalization did not precede them. Additional exclusions are shown in Supplementary Table S1. Readmissions are considered outcomes unless they have diagnosis or procedure codes that indicate a readmission was planned; ED visits are considered outcomes unless there was also an inpatient admission during the same 30-day window. Thus, for these paired measures, beneficiaries can have one of three outcomes: readmission, ED use without readmission, or no acute care event.

\section{Outcomes Regardless of Prior Hospitalization}

The second paired set of measures included in the study examines hospitalization and ED use without hospitalization in the first 60 days of home health enrollment, regardless of whether a hospitalization preceded the stay. The denominator for this sample was thus much larger, and the measures were calculated on 1 instead of 3 years of data. Fiscal year 2014 was used for this analysis. Similar to the 30-day measures described above, the 60-day measures excluded admissions for planned procedures or cancer therapy; 39,537 of the 3,306,496 stays in 2014 were excluded for this reason. Other exclusions are shown in Supplementary Table S2.

Our primary predictors for all four outcomes were beneficiary-level dual enrollment in Medicare and Medicaid, residence in a low-income neighborhood, and black race. Medicaid enrollment was obtained from Medicare enrollment data. Beneficiaries' home ZIP codes were linked with ZIP code tabulation areas (ZCTAs) using the Uniform Data Set mapper. ${ }^{12}$ To define low-income neighborhoods, all ZCTAs were ranked based on 5-year estimates of median household income from the American Community Survey. A cut-off for the lowest quintile of ZCTA-level income was determined using these rankings, weighted by the number of households in each ZCTA. Individuals with a most recent ZIP code of residence before the HHA admission date that were in a ZCTA with median household income below the cut-off were low income; the 1,491 stays $(0.06 \%)$ with ZIP codes that did not map to ZCTAs and the 4,467 stays $(0.12 \%)$ stays in ZCTAs with missing median household income were considered non-low income. To identify black beneficiaries, we used the race variable that Research Triangle International created (which is available in the enrollment database) rather than the raw race data, because this has previously been shown to improve the accuracy of race data in Medicare. ${ }^{13}$ To create a group of high-dual HHAs, we followed methods that have been used in the hospital safety-net literature, ${ }^{14,15}$ ranking all HHAs according to the proportion of dually enrolled beneficiaries served and creating a cutpoint that included $20 \%$ of all beneficiaries in the high-dual group. Because high-dual agencies tended to be small, this included more than $20 \%$ of agencies. A similar algorithm was followed to identify low-income ZCTA and high-black HHAs.

HHA location and size were obtained from Medicare home health files. Information on HHA quality was obtained from the publicly available Home Health Compare website, which provides ratings from one (worst) to five (best) stars for agencies participating in Medicare. ${ }^{16}$ CMS calculated the star ratings based on agency performance in 2014 and 2015 on a number of process and outcome measures.

\section{Analysis}

Summary statistics were calculated for beneficiary characteristics and agency characteristics for the denominator populations of the 30- and 60-day measures. 
Outcomes were calculated using multinomial logistic regression models, as specified in measure documentation. First, models were built with only the primary predictor to examine the overall risk of each clinical outcome for the population of interest. Generalized estimating equations were used for these models, which allowed us to examine outcomes across HHAs while still accounting for within-provider correlation. Next, random-effects models using HHA-specific random intercepts were used to examine outcomes within HHAs, which allowed us to determine the degree to which differences between dual and nondual or black and nonblack beneficiaries were related to different outcomes within the same HHAs versus use of different HHAs. For the random-effects models, an additional term for the proportion of each agency composed of the population of interest (dual, low-income neighborhood, black) was added to the models to control for potential residual confounding according to agency. Next, the full random-effects models with risk adjustment were run for each outcome. Variables included in the risk-adjustment model for the 30-day measures, following published measure specifications, ${ }^{11}$ included age, sex, disability, functional status, and comorbidities. A full list is provided in Supplementary Table S3. Risk adjustment for the 60-day models included similar factors and is provided in Supplementary Table S4. Finally, an additional model with full risk adjustment plus all of the primary predictors (dual status, neighborhood, race) was estimated to help determine the independent effect of each predictor.

\section{Table 1. Participant Characteristics}

\begin{tabular}{|c|c|c|c|c|c|c|}
\hline Characteristic & $\begin{array}{l}\text { Dually } \\
\text { Enrolled }\end{array}$ & $\begin{array}{l}\text { Not Dually } \\
\text { Enrolled }\end{array}$ & $\begin{array}{l}\text { Low-Income } \\
\text { Neighborhood }\end{array}$ & $\begin{array}{l}\text { Non-Low-Income } \\
\text { Neighborhood }\end{array}$ & Black & Not Black \\
\hline Stays, $\mathrm{n}^{\mathrm{a}}$ & 570,964 & $1,893,423$ & 518,090 & $1,946,297$ & 258,086 & $2,206,301$ \\
\hline Percentage of population & 23.2 & 76.8 & 21.0 & 79.0 & 10.5 & 89.5 \\
\hline Age, median & 70 & 77 & 74 & 76 & 71 & 76 \\
\hline Female, \% & 66.4 & 56.3 & 59.9 & 58.3 & 63.4 & 58.1 \\
\hline Dually eligible, \% & 100.0 & 0.0 & 37.5 & 19.4 & 48.2 & 20.2 \\
\hline Low-Income ZCTA, \% & 34.0 & 17.1 & 100.0 & 0.0 & 46.9 & 18.0 \\
\hline \multicolumn{7}{|l|}{ Race, \% } \\
\hline White & 56.9 & 88.2 & 65.7 & 85.0 & 0.0 & 90.4 \\
\hline Black & 21.8 & 7.1 & 23.3 & 7.0 & 100.0 & 0.0 \\
\hline Hispanic & 14.5 & 2.8 & 8.5 & 4.7 & 0.0 & 6.1 \\
\hline Asian or Pacific Islander & 4.7 & 0.8 & 1.0 & 1.9 & 0.0 & 1.9 \\
\hline Other & 0.8 & 0.5 & 0.4 & 0.6 & 0.0 & 0.6 \\
\hline Risk score, mean & 1.72 & 1.22 & 1.40 & 1.31 & 1.68 & 1.29 \\
\hline \multicolumn{7}{|l|}{ Number of comorbidities, \% } \\
\hline $0-2$ & 5.9 & 10.1 & 8.0 & 9.4 & 6.7 & 9.4 \\
\hline $3-5$ & 19.7 & 24.4 & 22.1 & 23.6 & 20.6 & 23.6 \\
\hline$\geq 6$ & 74.4 & 65.5 & 69.9 & 67.0 & 72.7 & 67.0 \\
\hline \multicolumn{7}{|l|}{ Comorbidities, \% } \\
\hline Ischemic heart disease & 32.8 & 33.9 & 34.3 & 33.5 & 30.5 & 34.0 \\
\hline Renal failure & 35.6 & 29.3 & 33.6 & 30.0 & 45.5 & 29.0 \\
\hline Heart failure & 32.0 & 28.1 & 30.9 & 28.5 & 35.4 & 28.3 \\
\hline Chronic obstructive pulmonary disease & 29.7 & 21.5 & 26.4 & 22.6 & 20.7 & 23.7 \\
\hline Depression & 19.4 & 13.7 & 15.0 & 15.0 & 11.0 & 15.5 \\
\hline Drug or alcohol & 22.1 & 9.7 & 16.8 & 11.4 & 17.3 & 12.0 \\
\hline Other psychiatric & 15.2 & 10.7 & 12.2 & 11.7 & 8.1 & 12.2 \\
\hline \multicolumn{7}{|l|}{ HHA, \% } \\
\hline High-dual & 27.2 & 8.2 & 21.5 & 10.3 & 21.5 & 11.6 \\
\hline Low-income ZIP code tabulation area & 22.2 & 14.5 & 46.2 & 8.4 & 24.7 & 15.4 \\
\hline High-black & 22.4 & 16.8 & 28.4 & 15.3 & 52.1 & 14.1 \\
\hline Urban & 93.7 & 95.1 & 88.2 & 96.5 & 95.7 & 94.6 \\
\hline For-profit & 51.1 & 47.4 & 55.5 & 46.3 & 53.2 & 47.7 \\
\hline \multicolumn{7}{|l|}{ Star rating, \% } \\
\hline $1.0-1.5$ & 0.4 & 0.2 & 0.4 & 0.2 & 0.3 & 0.3 \\
\hline $2.0-2.5$ & 14.4 & 11.2 & 15.5 & 11.0 & 15.2 & 11.6 \\
\hline $3.0-3.5$ & 54.2 & 55.8 & 54.0 & 55.8 & 55.4 & 55.4 \\
\hline $4.0-5.0$ & 27.8 & 30.6 & 27.3 & 30.7 & 26.2 & 30.4 \\
\hline Not available & 3.2 & 2.2 & 2.8 & 2.3 & 2.8 & 2.4 \\
\hline
\end{tabular}

Participant characteristics shown here are based on the 30-day measures. See Supplementary Table S5 for similar table for 60-day measures.

Comorbidities are based on the hierarchical condition categories used in the risk adjustment models for home health outcome measures. Categories are not mutually exclusive.

${ }^{\mathrm{a}} \mathrm{A}$ home health stay for purposes of the measure was a 60 -day home health episode separated from other episodes by at least 60 days that met measure inclusion criteria.

${ }^{\mathrm{b}} \mathrm{A}$ missing star rating can be because the home health agency (HHA) was not open long enough or the agency was too small to receive a rating. Provider categories are not mutually exclusive. 
Because of the de-identified nature of the data, this was not considered human subjects research. Analyses were performed using SAS (SAS Institute, Inc., Cary, NC); two-sided $P<.05$ was considered statistically significant.

\section{RESULTS}

\section{Participant Characteristics}

Of the 2,464,387 home health stays in the sample for the 30-day readmission and ED use measures, 570,964 $(23.2 \%)$ were for dually enrolled beneficiaries, 518,090 $(21.0 \%)$ for individuals in low-income neighborhoods, and $258,086(10.5 \%)$ for black beneficiaries (Table 1$)$. Dually enrolled, low-income neighborhood, and black beneficiaries were younger and had higher clinical risk scores, representing a higher burden of comorbidities, than their counterparts. Patterns were similar when considering stays included in the 60-day admission and ED use measures (Supplementary Table S5).

\section{Agency Characteristics and Quality}

There were 11,774 home health agencies in the sample, of which $5,113(43.4 \%)$ were in the high-dual group, $4,085(34.7 \%)$ in the low-income ZCTA group, and $3,637(30.9 \%)$ in the high-black group; these agencies provided $12.6 \%, 16.3 \%$, and $18.1 \%$ of home health stays, respectively, during the study period (Table 2). High-dual, low-income ZCTA, and high-black agencies had fewer stays per provider and were more often for profit in ownership. High-dual agencies (18.1\%), lowincome ZCTA agencies $(16.8 \%)$, and high-black agencies $(15.1 \%)$ were less likely to receive 4 - or 5-star ratings based on 2014-15 performance than their peers and more likely to have no star rating, generally because of small sample size. Findings were similar for the sample of agencies included in the 60-day admission and ED use measures (Supplementary Table S6).

\section{Raw Rates of 30- and 60-Day Adverse Clinical Outcomes}

In unadjusted analyses, dually enrolled beneficiaries had significantly higher rates of all four clinical outcomes examined: 30 -day readmissions $(16.0 \%$ vs $12.3 \%$, $P<.001)$, 30-day ED use without readmission $(11.7 \%$ vs $8.1 \%, P<.001), 60$-day admissions $(15.9 \%$ vs $15.4 \%$, $P<.001)$, and 60-day ED use without admission $(13.7 \%$ vs $11.3 \%, P<.001$, Figure $1 \mathrm{~A})$. Beneficiaries in lowincome neighborhoods had higher rates of 30-day readmission, 30-day ED use and 60-day ED use (Figure 1B). Black beneficiaries had higher rates of all four adverse clinical outcomes (Figure 1C).

\section{Relationship Between Poverty, Neighborhood, Race, and Clinical Outcomes}

Dually enrolled beneficiaries (odds ratio $(\mathrm{OR})=1.44$, $P<.001$ ), beneficiaries living in a low-income neighborhood $(\mathrm{OR}=1.16, \quad P<.001)$, and black beneficiaries $(\mathrm{OR}=1.31, P<.001)$ all had higher odds of 30-day readmission (Table 3). In all cases, when a random effect for home health agency was added to the model, the odds fell slightly or increased, suggesting that the majority of the greater risk was within agency-associated with the individual's characteristics rather than the agency from which care was received (Table 3 ).

When risk-adjustment variables, such as age and medical comorbidities, were added to the random-effects models, the odds of each clinical outcome associated with the social risk factors of interest dropped considerably but remained significant in all cases (Table 3). For example, with risk adjustment, the odds of 30-day readmission for a

Table 2. Home Health Agency (HHA) Characteristics

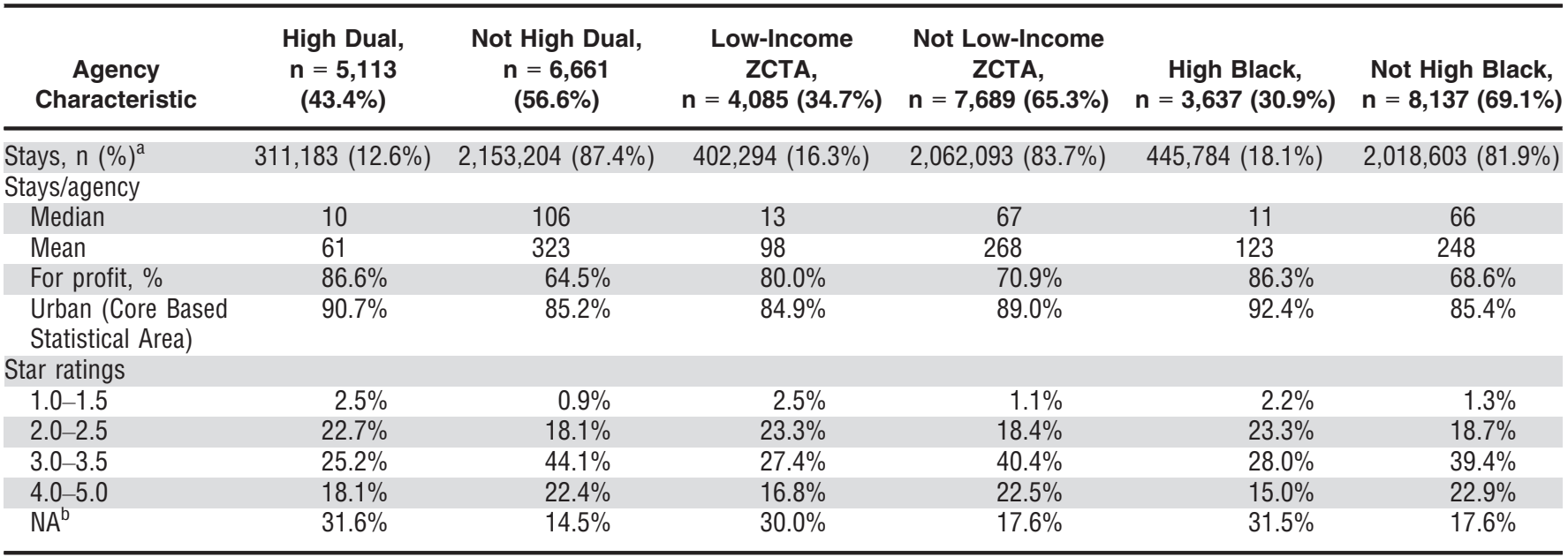

Agency characteristics shown here are based on the 30-day measures. See Supplementary Table S6 for similar table for 60-day measures.

Provider categories are not mutually exclusive.

${ }^{\mathrm{a}} \mathrm{A}$ home health stay for purposes of the measure is a 60 -day home health episode separated from other episodes by at least 60 days that meets measure inclusion criteria.

${ }^{\mathrm{b}} \mathrm{A}$ missing star rating can be because the HHA was not open long enough or the agency was too small to receive a rating. 


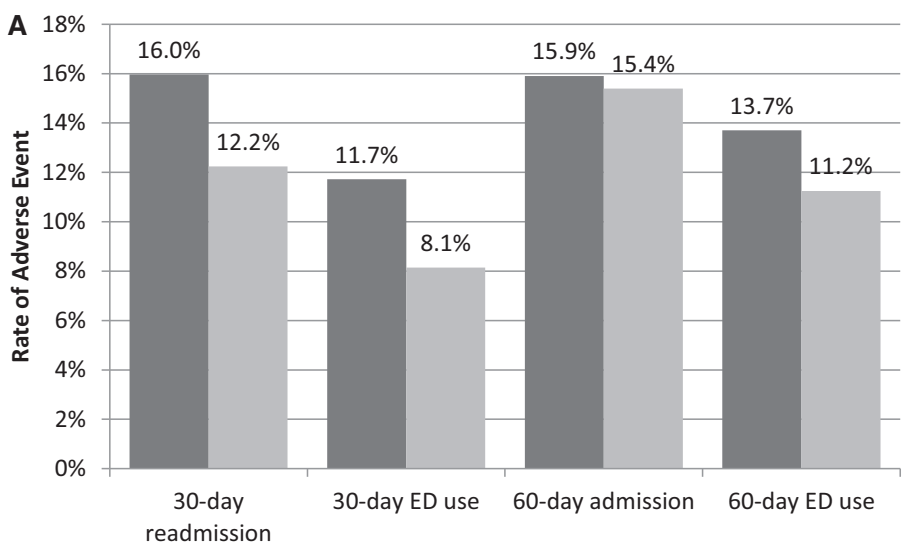

$$
\begin{aligned}
& \text { Dually-Enrolled } \\
& \text { Not Dually-Enrolled }
\end{aligned}
$$

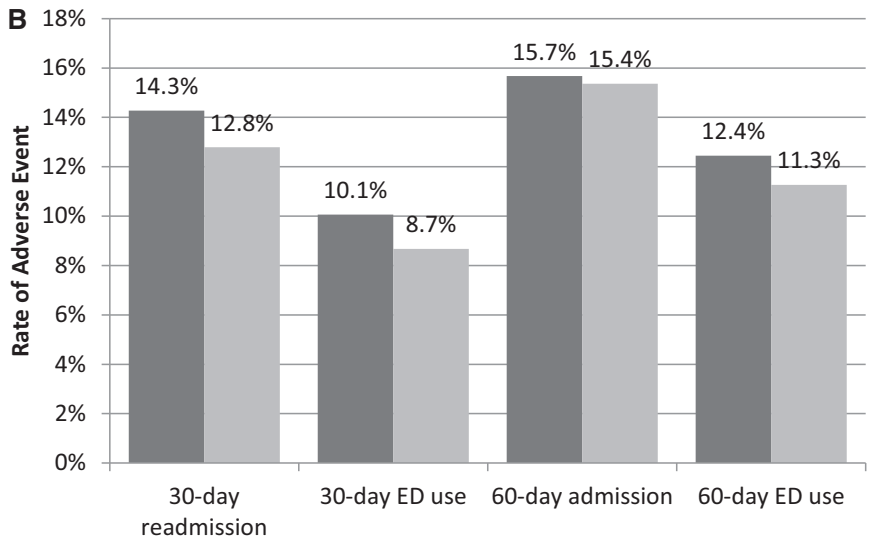

- Low-Income ZCTA

Non-Low-Income ZCTA

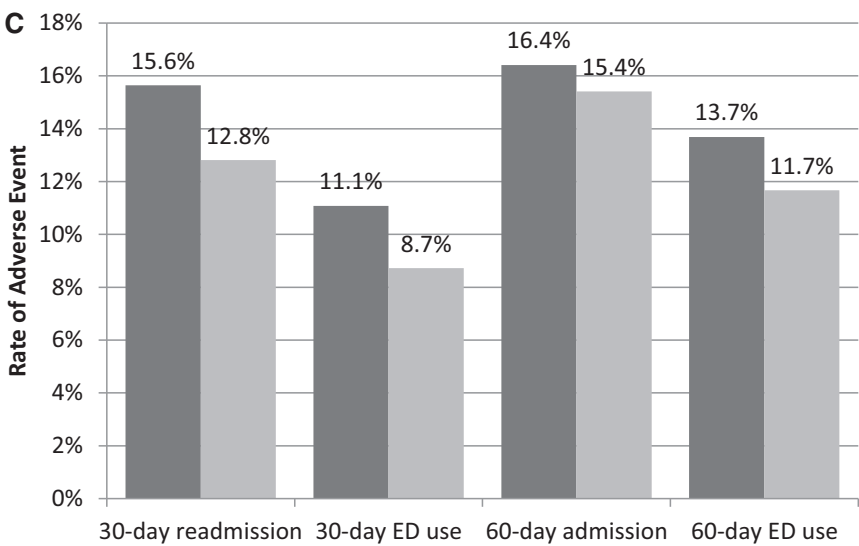

- Black

Non-Black

Figure 1. 30- and 60-day clinical outcomes. Rates of adverse clinical outcomes for (A) dually enrolled vs non-dually enrolled, (B) low-income neighborhood vs non-low-income neighborhood, and (C) black vs. non-black beneficiaries. ED = emergency department. $P<.001$ for all comparisons except for low-income ZIP code tabulation area (ZCTA) beneficiaries' 60-day admission comparison $(P=.80)$.

dually enrolled beneficiary dropped to 1.08. After risk adjustment, the largest ORs were seen for 30- and 60-day ED use without hospital admission, with $15 \%$ to $20 \%$ higher odds of this outcome for dually enrolled and black beneficiaries than for their counterparts even after controlling for comorbidities and even using models to isolate the within-agency effect of each factor.

Finally, when all risk factors were entered into a single model for each outcome, dual enrollment remained significantly associated with higher odds of each adverse clinical outcome (Table 3), whereas the effect of low-income neighborhood residence was nearly eliminated. The association between black race and higher odds of adverse clinical outcomes remained significant for all outcomes except 30-day readmission, although relationships were attenuated somewhat.

\section{DISCUSSION}

Dually enrolled beneficiaries, those living in low-income neighborhoods, and black beneficiaries receiving home health care were more likely to receive care from lowerrated agencies and agencies that did not receive a star rating than their counterparts. They also had higher rates of 30-day readmission and ED use and 60-day admission and $\mathrm{ED}$ use; these differences were diminished by controlling 
Table 3. Beneficiary-Level Social Risk Factors and Clinical Outcomes

\begin{tabular}{cccc} 
& $\begin{array}{c}\text { Within Agency } \\
\text { (Random-Effects } \\
\text { Model) }\end{array}$ & $\begin{array}{c}\text { Risk Adjusted Within } \\
\text { Agency (Random-Effects } \\
\text { Model with Risk Adjustment) }\end{array}$ & $\begin{array}{c}\text { Risk Adjusted Within Agency } \\
\text { (Random-Effects Model with Risk } \\
\text { Total }\end{array}$ \\
\hline
\end{tabular}

Social Risk Factor

\begin{tabular}{|c|c|c|c|c|}
\hline \multicolumn{5}{|l|}{ 30-day readmission } \\
\hline Dually enrolled & $1.44,<.001$ & $1.41,<.001$ & $1.08,<.001$ & $1.08,<.001$ \\
\hline Low-income ZCTA & $1.16,<.001$ & $1.14,<.001$ & $1.03,<.001$ & $1.02,<.001$ \\
\hline Black & $1.31,<.001$ & $1.28,<.001$ & $1.02, .002$ & $1.00, .61$ \\
\hline Dually enrolled & $1.58,<.001$ & $1.59,<.001$ & $1.20,<.001$ & $1.18,<.001$ \\
\hline Low-income ZCTA & $1.20,<.001$ & $1.17,<.001$ & $1.07,<.001$ & $1.03,<.001$ \\
\hline Black & $1.36,<.001$ & $1.39,<.001$ & $1.15,<.001$ & $1.11,<.001$ \\
\hline Low-income ZCTA & $1.01, .10$ & $1.07,<.001$ & $1.01, .002$ & $1.00, .667$ \\
\hline Black & $1.11,<.001$ & $1.15,<.001$ & $1.05,<.001$ & $1.04,<.001$ \\
\hline \multicolumn{5}{|l|}{ 60-day ED use } \\
\hline Dually enrolled & $1.27,<.001$ & $1.39,<.001$ & $1.16,<.001$ & $1.15,<.001$ \\
\hline Low-income ZCTA & $1.08,<.001$ & $1.09,<.001$ & $1.03,<.001$ & $1.00, .39$ \\
\hline Black & $1.22,<.001$ & $1.27,<.001$ & $1.19,<.001$ & $1.17,<.001$ \\
\hline
\end{tabular}

${ }^{a}$ Calculated from generalized estimating equations models with an independent correlation matrix, which gives the total (within and between home health agencies (HHAs)) effect of the social risk factor in each row.

Random effects models include a random effect for agency and an additional term for HHA social risk makeup (high vs low proportion of the social risk factor) to isolate the within-facility effect of the social risk factor in question.

ZCTA = ZIP code tabulation area; ED = emergency department.

for differences in comorbidities, but where they persisted, they reflected different outcomes within HHAs, rather than an effect related to the agencies from which these beneficiaries sought care.

Our first finding was that dually enrolled, lowincome, and black beneficiaries were more likely to receive care from HHAs with lower star ratings or agencies that did not receive any rating because of inadequate data, although the fact that the time frame for our claims-based measures and the publicly reported star ratings do not overlap perfectly somewhat limit these findings. The star ratings are based on a broader range of factors than the clinical outcomes we examined, including process measures such as influenza immunization and outcome measures such as improvement in functional status and pain. ${ }^{17}$ The reasons these beneficiaries disproportionately receive care from low-star (and no-star) agencies are unclear. They may have fewer choices of HHAs based on the availability of high-quality agencies in their service area or may be less likely to comparison shop for high-quality agencies. Alternatively, there may be a structural feature, such as profit status, that is associated with the type of individuals it serves and the star rating; for example, forprofit home health agencies have somewhat lower performance on quality measures. ${ }^{18}$ If they also serve a higher proportion of poor or minority individuals, this could in part mediate these relationships. Further study to understand the factors that influence home health agency choice of vulnerable populations may be an important component in efforts toward improving equity in home health care.

We also found significant differences in admission and readmission rates according to dual status and race that were of similar magnitude to disparities that have been previously reported outside the home health setting, ${ }^{19-21}$ but the highest odds associated with dual enrollment or black race were those for 30- and 60-day ED use without admission, even after adjusting for clinical risk and even when compared with other beneficiaries within the same HHAs; this suggests that the reasons underlying these patterns are likely to be related to individual rather than agency factors. Lack of a usual source of care, ${ }^{22}$ lowerquality primary care, ${ }^{23}$ barriers to seeking non-ED care (e.g., hours, transportation), ${ }^{24}$ language barriers, mistrust, culturally insensitive care, ${ }^{25}$ and less experience navigating the healthcare system, ${ }^{24}$ all of which is have previously been demonstrated that individuals in poverty and racial minorities more commonly experience, may contribute to these findings.

Our findings may have implications as HHAs prepare for a move to value-based purchasing models, which will reward providers for high quality and good clinical outcomes. Understanding the underlying reasons why there are disparities for dually enrolled and black beneficiaries in home health care-for example, whether preventable ED visits $^{26}$ are primarily related to access to care as discussed above or whether they are due to other critical but less easily measured factors such as higher levels of frailty or lower levels of social support ${ }^{27,28}$-is an important next step in designing interventions to reduce them. Such knowledge may be critical as clinical leaders and policymakers seek to harness value-based payment in the home health setting to improve care and clinical outcomes while not inappropriately penalizing providers for factors beyond their control.

Our study adds to a growing body of literature documenting disparities in clinical outcomes for poor and minority individuals and extends it to the home healthcare 
setting. For example, prior work has shown that, of all discharged individuals (not just those discharged to home health), dually enrolled beneficiaries had $15 \%$ higher odds of readmission after a hospitalization and that black beneficiaries had $13 \%$ to $19 \%$ higher odds of readmission. ${ }^{19,21}$ We found slightly smaller effects, which may in part be related to the differences in the factors included in risk adjustment for the HHA readmission measure and the hospital readmission measure, because of the composite nature of this measure, or because of true differences in the underlying relationships. Similarly, prior work has documented higher rates of preventable admission and ED use among dually eligible and black beneficiaries outside the home health setting, although direct comparison of effect size is difficult given differences in methodology. ${ }^{29-31}$

There are limitations to our study. We examined outcomes only of Medicare fee-for-service beneficiaries, and whether patterns would hold in other populations is unclear. Clinical risk adjustment relies on coded comorbidities, which may underestimate actual comorbidities. The time frame for the claims-based measures and star ratings do not overlap perfectly. Although we anticipate that the racial and economic makeup of the agencies is relatively stable over time, any major shifts in demographic characteristics that occurred could have led us to misclassify agencies. Finally, whether disparities in clinical outcomes will change under the financial incentives in the HHVBP program or other postacute value-based payment models remains to be seen but should be monitored closely.

In conclusion, Medicare beneficiaries receiving home health services who are poor or black tend to receive care from lower-quality home health agencies and have higher rates of adverse clinical outcomes such as admission, readmission, and ED use. Reducing disparities in access to and delivery of high-quality home health care may be important in avoiding any potential unintended consequences of value-based payment programs in the home health setting.

\section{ACKNOWLEDGMENTS}

Conflict of Interest: There are no financial or personal conflicts of interest to report. All authors are or were employees or contractors for the U.S. Department of Health and Human Services during the time the work was performed.

Author Contributions: Study concept and design: Joynt, Chen, Zuckerman, Epstein. Acquisition of subjects and/or data: Joynt, Chen, Zuckerman, Epstein. Analysis and interpretation of data: Joynt, Chen, Zuckerman, Epstein. Preparation of manuscript: Joynt, Chen, Zuckerman, Epstein.

Sponsor's Role: There was no specific funding for this project. It was completed as part of employment at HHS.

\section{REFERENCES}

1. Medicare Payment Advisory Commission. March 2016 Report to the Congress: Medicare Payment Policy. Washington, DC: Medicare Payment Advisory Commission, 2016.

2. Department of Health and Human Services, Administration for Community Living, Administration on Aging. Aging Statistics 2016 [on-line]. Available at https://aoa.acl.gov/Aging_Statistics/Index.aspx Accessed March 22, 2017.
3. Centers for Medicare and Medicaid Services. Home Health Value-Based Purchasing Model 2016 [on-line]. Available at https://innovation.cms.gov/ initiatives/home-health-value-based-purchasing-model Accessed October 23, 2016.

4. Joynt KE, Jha AK. Characteristics of hospitals receiving penalties under the Hospital Readmissions Reduction Program. JAMA 2013;309:342-343.

5. Gilman M, Adams EK, Hockenberry JM et al. Safety-net hospitals more likely than other hospitals to fare poorly under Medicare's value-based purchasing. Health Aff (Millwood) 2015;34:398-405.

6. Ryan AM. Will value-based purchasing increase disparities in care? N Engl J Med 2013;369:2472-2474.

7. Brega AG, Goodrich GK, Powell MC et al. Racial and ethnic disparities in the outcomes of elderly home care recipients. Home Health Care Serv Q $2005 ; 24: 1-21$.

8. Smith LM, Anderson WL, Kenyon A et al. Racial and ethnic disparities in patients' experience with skilled home health care services. Med Care Res Rev 2015;72:756-774.

9. Chen HF, Homan S, Carlson E et al. The impact of race and neighborhood racial composition on preventable readmissions for diabetic Medicare home health beneficiaries. J Racial Ethn Health Disparities 2017;4:648-658.

10. Office of the Assistant Secretary for Planning and Evaluation. Report to Congress: Social Risk Factors and Performance Under Medicare's ValueBased Purchasing Programs. Washington, DC: U.S. Department of Health \& Human Services, 2016.

11. Centers for Medicare and Medicaid Services. Home Health Quality Initiative: Quality Measures 2016 [on-line]. Available at https://www.cms.gov/ Medicare/Quality-Initiatives-Patient-Assessment-Instruments/HomeHealth QualityInits/HHQIQualityMeasures.html Accessed November 21, 2016.

12. American Academy of Family Physicians. UDS Mapper 2017 [on-line]. Available at https://www.udsmapper.org Accessed July 20, 2017.

13. Eicheldinger C, Bonito A. More accurate racial and ethnic codes for Medicare administrative data. Health Care Financ Rev 2008;29:27-42.

14. Chatterjee P, Joynt KE, Orav EJ et al. Patient experience in safety-net hospitals: Implications for improving care and value-based purchasing. Arch Intern Med 2012;172:1204-1210.

15. Gilman M, Hockenberry JM, Adams EK et al. The financial effect of value-based purchasing and the hospital readmissions reduction program on safety-net hospitals in 2014: A cohort study. Ann Intern Med 2015;163:427-436.

16. U.S. Department of Health \& Human Services. Home Health Compare [on-line]. Available at https://www.medicare.gov/homehealthcompare/searc h.html Accessed January 14, 2016.

17. Centers for Medicare and Medicaid Services. Home Health Star Ratings 2016 [on-line]. Available at https://www.cms.gov/Medicare/Quality-Initia tives-Patient-Assessment-instruments/HomeHealthQualityInits/HHQIHome HealthStarRatings.html Accessed October 23, 2016.

18. Cabin W, Himmelstein DU, Siman ML et al. For-profit medicare home health agencies' costs appear higher and quality appears lower compared to nonprofit agencies. Health Aff (Millwood) 2014;33:1460-1465.

19. Tsai TC, Orav EJ, Joynt KE. Disparities in surgical 30-day readmission rates for Medicare beneficiaries by race and site of care. Ann Surg 2014;259:1086-1090.

20. Jiang HJ, Wier LM. All-Cause Hospital Readmissions among Non-Elderly Medicaid Patients, 2007. Healthcare Cost and Utilization Project 2010; HCUP Statistical Brief \#89 [on-line]. Available at http://www.hcup-us.ahrq. gov/reports/statbriefs/sb89.pdf. Accessed on August 24, 2017

21. Joynt KE, Orav E, Jha AK. Thirty-day readmission rates for Medicare beneficiaries by race and site of care. JAMA 2011;305:675-681.

22. National Center for Health Statistics. Access to Health Care 2016 [on-line]. Available at http://www.cdc.gov/nchs/fastats/access-to-health-care.htm Accessed November 21, 2016.

23. Bach PB, Pham HH, Schrag D et al. Primary care physicians who treat blacks and whites. N Engl J Med 2004;351:575-584.

24. Kangovi S, Barg FK, Carter T et al. Understanding why patients of low socioeconomic status prefer hospitals over ambulatory care. Health Aff (Millwood) 2013;32:1196-1203.

25. Arnett MJ, Thorpe RJ Jr, Gaskin DJ et al. Race, medical mistrust, and segregation in primary care as usual source of care: Findings from the Exploring Health Disparities in Integrated Communities Study. J Urban Health 2016;93:456-467.

26. Ballard DW, Price M, Fung V et al. Validation of an algorithm for categorizing the severity of hospital emergency department visits. Med Care 2010;48:58-63.

27. Kahlon S, Pederson J, Majumdar SR et al. Association between frailty and 30-day outcomes after discharge from hospital. Can Med Assoc J 2015;187:799-804. 
28. Arbaje AI, Wolff JL, Yu Q et al. Postdischarge environmental and socioeconomic factors and the likelihood of early hospital readmission among community-dwelling Medicare beneficiaries. Gerontologist 2008;48:495504.

29. Mukamel DB, Ladd H, Li Y et al. Have racial disparities in ambulatory care sensitive admissions abated over time? Med Care 2015;53:931-939.

30. Dresden SM, Feinglass JM, Kang R et al. Ambulatory care sensitive hospitalizations through the emergency department by payer: Comparing 2003 and 2009. J Emerg Med 2016;50:135-142.

31. Wright B, Potter AJ, Trivedi A. Federally qualified health center use among dual eligibles: Rates of hospitalizations and emergency department visits. Health Aff (Millwood) 2015;34:1147-1155.

\section{SUPPORTING INFORMATION}

Additional Supporting Information may be found in the online version of this article:
Table S1. Exclusions from 30-Day Measures

Table S2. Exclusions from 60-Day Measures

Table S3. Risk Adjustment Variables, 30-Day measures

Table S4. Risk Adjustment Variables, 60-Day measures

Table S5. Patient Characteristics, 60-Day Measures

Table S6. Home Health Agency Characteristics, 60Day Measures

Please note: Wiley-Blackwell is not responsible for the content, accuracy, errors, or functionality of any supporting materials supplied by the authors. Any queries (other than missing material) should be directed to the corresponding author for the article. 